\title{
O POEMA, UM ANIMAL QUE RI
}

\author{
The POEM, A LAUGHING ANIMAL
}

\author{
Manoel Ricardo de Lima* \\ Universidade Federal do Estado do Rio de Janeiro - Unirio
}

\begin{abstract}
RES U M O
Este trabalho parte da pequena narrativa de Gonçalo M. Tavares, intitulada "O animal de Calvino", e do poema de Max Martins, intitulado "O animal sorri", para estabelecer uma linha de pensamento que tenta tocar o lugar do poeta, numa perspectiva póshumana, entre a constituição de um ethos e de um centro móvel e político do tempo agora.
\end{abstract}

PALAVRAS-CHAVE

Poema, política, animalidade

Esta metamorfose de homens em animais e animais em homens é uma indicação segura da maneira pela qual o homem considerava o animal como o seu igual.

(Flavio de Carvalho, A origem animal de Deus)

Ao indicar que o Brasil tem outros fundos, mesmo se numa memória bíblica, cristã, ou numa memória de cegos, para usar uma expressão de Jacques Derrida, é possível pensar em Jeremias, a personagem protagonista do romance de Assis Brasil, publicado em 1975, intitulado Os que bebem como os cães. A imagem disseminada em toda a narrativa é a de Jeremias, um homem que se arrasta preso numa cela sem conseguir pensar, logo, sem conseguir dizer e ver, qual o motivo que o levou até ali, entre um pátio composto de restos humanos, restos de comida e uma série avariada de gritos de desespero, tortura e suicídios, à espera de um rato e recuperando algo das Lamentações, do profeta Jeremias: "desgraçados de nós porque pecamos." A circunstância aberta pela personagem de Assis Brasil é de medo e ex-crição: um homem com um estômago contraído que expele a si mesmo "como um animal em sua última fome". ${ }^{1} \mathrm{O}$ tempo perdido e medido por Jeremias na prisão se estabelece entre uma espera sem cansaço e a aparição do rato na cela, como uma presença de Deus. Mas Jeremias não sabe se o rato vem de fato, se o rato é fruto de sua imaginação, se há algo "de fato", se há "imaginação", se o rato se deixaria ver e se é rato porque se deixa ver. Assim, dá ao rato a sua comida rala em seu

\footnotetext{
*manoelrl@uol.com.br

${ }^{1}$ BRASIL. Os que bebem como os cães, p. 124.
} 
próprio prato, ou seja, dividir o prato com o rato é não só uma compensação à companhia, mas também uma atração e uma metamorfose. Uma reconciliação? Note-se em três passagens da narrativa: "tenho que medir o meu tempo", "ele vai voltar na mesma hora", "o hábito da espera era a sua glória e o seu reino" (ou seja, há aí um paradigma teológico-político, se quisermos pensar com Giorgio Agamben, a partir de seu livro - não à toa - chamado Il regno e la gloria.Per una genealogia teologica dell'economia e del governo. Homo sacer, de 2007: rever os traços de uma economia animal ou do mistério prático-político de uma separação entre o animal e o humano). A conclusão de Jeremias é, diz ele, "o homem não pode".

Essa proposição categórica e interrompida, o homem não pode, remete a outra personagem, de nome Simplício, do romance de Joaquim Manuel de Macedo, publicado em 1869, A luneta mágica, numa outra figuração da mesma imagem, quase cega. Simplício é míope e, segundo ele mesmo, desde o nome, esta falta, duplamente míope: uma miopia moral, outra física; numa espécie de anabasis da proposição. Simplício é levado por um amigo até um misterioso armênio que, dotado de poderes mágicos, consegue-lhe uma luneta, através da qual é possível atenuar sua miopia e ver com clareza (o que pode ser um contrassenso), porém com perspectiva radicalmente polar: ou o bem ou o mal. Essa condição polar comparece como um começar para um campo de ação possível dos primeiros romances de nossa literatura no século 19: quando o romance e a prosa não coincidem, como sugere Michel Deguy.

Enfim, o uso do monóculo implica a restrição de que seu usuário não fixe os olhos sobre qualquer coisa por mais de três minutos, "tempo da visão das aparências", diz o armênio; porque a partir daí descortina-se o mundo bom ou o mundo mal e, assim, é preciso dizer do mundo. Entre os capítulos 32 e 39, de posse da luneta do mal, Simplício encontra-se febril, dado como louco por sua parentalha, em seu quartinho de sótão, abandonado em sua cama, este lugar imposto como seguro, até a metamorfose de Gregor Samsa (Franz Kafka), com um sono fingido e a luneta atada em sua perna esquerda, quase como uma prótese, uma endogenia. Vigiado por escravos e cansado de esperar, pega a luneta e a fixa nos pequenos insetos que o circundam no quartinho: "Que maldade em corpos tão pequenos." ${ }^{3}$ Entre os bichos estão um grilo, um gafanhoto, uma pulga, um mosquito, um cupim, uma aranha e, por fim, um rato que não se deixa ver. Do grilo e do gafanhoto constata que não são melhores que os homens; da pulga diz que é como um homem sem generosidade: cruel, parasita sanguinária, ataca sem ser vista. Dos mosquitos, diz que enxergam muito mais que os estadistas do Império; da aranha, que, assim como os homens, guerreia e mata os de sua própria espécie sem precisão de fome e é o modelo exato de centralização política e administrativa daquele Brasil; do rato que não viu consegue dizer que, por isso, é um trapaceiro: não se deixa ver. Mas é quando diz do cupim que a narrativa se articula como um acidente para a metamorfose: para ele o cupim aniquila tanto ou mais que certos ministros da fazenda e de obras públicas que se espalham pelo Império do Brasil; o cupim tem também um pacto de amizade com livreiros, alfaiates e carpinteiros; ele desmonta objetos e com a sua roedura devolve a essas tarefas alguma possibilidade de lucro. O cupim, diz esse homem-Simplício, é um inseto-monstro,

${ }^{2}$ BRASIL. Os que bebem como os cães, p. 137.

${ }^{3}$ MACEDO. A luneta mágica, p. 102. 
um fora da lei, logo, é um transgressor; assim, é o cupim que mantém a impureza da imagem, a luta das imagens, a imagem viva.

Esses gestos transgressores de Jeremias e Simplício com o rato - o homem não pode / o homem não vê - e do cupim percebido por Simplício - aquele que é fora da lei - se ponderados como ex-crição do sentido, quando o sentido não é significado, e como uma quirição ao tempo perdido, como afronta - podem ser rearmados com mais sofisticação numa carta e num poema de Joaquim Cardozo. Em 1956, Joaquim Cardozo envia uma carta ao amigo Oscar Niemeyer e, nela, infere a partir de uma anamnese, uma rearticulação da metamorfose para a constituição de seu pensamento em torno do poema: um pequeno animal que perdeu as asas e metamorfoseia-se a um livro de arte:

Imagine que um dia desses resolvi arrumar os meus livros. Lembrei-me, então, de um livro que comprara na Europa, um exemplar de luxo, impresso em papel japão, uma beleza! De repente, encontrei o volume num cantinho da estante. Ao abri-lo, porém, verifiquei que estava todo comido pelas traças. A princípio eu fiquei triste. Depois, olhando bem, vi que o livro estava mais bonito: as traças construíram lá dentro um verdadeiro labirinto. Uma maravilha! ${ }^{4}$

Há aí, para Joaquim Cardozo, no cupim com o livro, uma forma-formante, uma espécie de associação ou extensão disjuntiva da linguagem como um estado de ficção que é gerado a partir de um esforço - no cálculo estrutural, ofício de Joaquim Cardozo, esforço é uma espécie de teoria da deformação, ou seja, no cálculo estrutural, tudo é feito para que não se deforme nem deforme o "real" daquilo que constrói; para Joaquim Cardozo isso é um "estágio da experimentação em que o corpo se deformando começa a deformar, por sua vez, o corpo deformador"; depois, esse estado de ficção vem também e ao mesmo tempo de uma experiência irrecuperável, entre a imaginação e algum procedimento, como se num movimento browniano de matizes. ${ }^{5}$ Tanto que essa anamnese, anos depois,

\footnotetext{
${ }^{4}$ CARDOZO. Poesia completa.

${ }^{5}$ Em 1928, foi publicado, na revista científica inglesa Philosophical Magazine, um artigo com o simpático título "Uma breve descrição de observações microscópicas efetuadas nos meses de junho, julho e agosto de 1827 sobre partículas contidas no pólen de plantas". Seu autor, o botânico Robert Brown, observou, através do microscópio, pequenos grãos de pólen de plantas tão leves que flutuavam dentro d'água. O que ele achou surpreendente e inexplicável foi o movimento incessante desses grãos, deslocando-se de um lado para o outro em uma dança brusca. Inicialmente, Brown pensou que esse movimento fosse causado por algum minúsculo ser vivo morando dentro do grão. Mas depois observou o mesmo tipo de comportamento em partículas de cinza e poeira flutuando em água. Um movimento associado ao movimento das moléculas da água. A explicação completa e rigorosa do movimento browniano foi dada pelo jovem Albert Einstein, em 1905. Nesse ano, Einstein publicou uns poucos artigos que abalaram a Física. Um deles se intitulava "Sobre o movimento de partículas suspensas em um fluido em repouso". O caminho que uma partícula browniana percorre é irregular e imprevisível. Não dá para descrever rigorosamente essa trajetória, nem com palavras nem com uma expressão matemática. Aliás, os matemáticos sofrem um bocado com esse tipo de "curva", toda feita de ângulos e desvios súbitos. Tecnicamente, eles dizem que essa curva é "patológica", uma curva contínua, mas não tem derivada contínua em nenhum de seus pontos. Alguns anos depois do trabalho de Einstein, o matemático Nobert Wiener provou que a trajetória browniana tem comprimento infinito entre dois pontos quaisquer. O caminho traçado pela partícula é tão enrolado que, se esperássemos um tempo infinitamente longo, ela percorreria todo o plano, sem deixar de passar por nenhum ponto. Tecnicamente se diz que, contrariando as aparências, o caminho percorrido pela partícula browniana não é uma linha (com dimensão), mas é uma superfície (com dimensão). A trajetória da partícula browniana é irregular, com um microscópio potente é possível ver que a curva é muito angulosa e irregular.
} 
num desdobramento da anotação íntima da carta, resulta num poema interessantíssimo de seu livro Mundos paralelos, de 1970, intitulado "A escultura folheada":

"A escultura folheada"

Aqui está um livro

Um livro de gravuras coloridas;

Na parte superior da capa deste livro

Há um ponto-furo: um simples ponto

simples furo

E nada mais.

Abro a capa do livro e

Vejo por trás da mesma que o furo continua;

Folheio as páginas, uma a uma.

- Vou passando as folhas, devagar,

o furo continua.

Noto que, de repente, o furo vai se alargando

Se abrindo, florindo, emprenhando,

Compondo um volume vazio, irregular, interior e conexo:

Superpostas aberturas recortadas nas folhas do livro.

Têm a forma rara de uma escultura vazia e fechada,

Uma variedade, uma escultura guardada dentro de um livro,

Escultura de nada: ou antes, de um pseudo-não;

Fechada, escondida, para todos os que não quiserem

Folhear o livro.

Mas, prossigo desfolhando:

Agora a forma vai de novo se estreitando

Se afunilando, se reduzindo, desaparecendo/surgindo

E na capa do outro lado se tornando

novamente

Um ponto-furo, um simples ponto

simples furo

E nada mais.

Os seres que a construíram, simples formigas aladas,

Evoluíam sob o sol de uma lâmpada

Onde perderam as asas. Caíram.

As linhas de vôo, incertas e belas, aluíram;

Mas essas linhas volantes, a princípio, foram

Se reproduzindo nas folhas do livro, compondo desenhos

De fazer inveja aos mais "sábios artistas". 
Circunvagueando, indecisas nas primeiras páginas,

À procura da forma formante e formada.

Seus vôos transcritos, "refletidos" nessas primeiras linhas,

Enfim se aprofundam, se avolumam no vazio

De uma escultura escondida, no escuro do interno;

Somente visível, "de fora", por dois pontos;

Dois pontos furos: simples pontos

simples furos

E nada mais. ${ }^{6}$

Ficamos assim diante do evento, de uma visão do invisível, de uma vinda, de uma visitação, de um acontecimento, de um porvir. Por isso, diz Derrida,

é preciso inscrever a memória do evento para dar graças. Observar a lei para além da vista, ordenar a verdade à dívida, dar graças ao dom e à falta, ao devido, à falha do é preciso [il faut]: do é preciso ver [il faut voir], de um resta ver [il reste à voir] que conota ao mesmo tempo a superabundância e a fraqueza do visível, o demasiado e o demasiado pouco, o excesso e a falência. ${ }^{?}$

Quando o poema, me parece, é uma observação, uma ética: aquilo que é para "tomar uma satisfação" (como está num pequeno poema de Horácio Dídimo intitulado "O pássaro", porque toda ética é falta, e é porque ela está sempre em falta que ela é justamente precisa, afirma Derrida. Michel Deguy ${ }^{9}$ reelabora essa questão, me parece, ao comentar uma tradução de um verso de um poema de Hölderlin, de 1808, "Andenken" ["Memória"]: "Was Bleibet aber, stiften die Dichter." - "Mas o que permanece, os poetas o fundam." Ao preferir, numa virtualização do verso, "os restos, a arte os reexpõe" e, ainda, "aquilo, os poetas o reexpõem".

Num modo de operação crítica daquilo que Michel Deguy propõe como saída da representação, é possível - ao tomar como exemplo esse poema de Joaquim Cardozo, desdobrado das imagens de Jeremias e Simplício, por que não? - dizer que o poema comparece como uma "experiência compatível" (poesia e prosa, poesia com prosa, poesia e filosofia, poesia e artes visuais, poesia e política, poesia, etc.) porque vem como "uma arqueologia incansável do pensamento": DIZER. Para Michel Deguy, nos resta dizer, o poema é um Dichtung (Heidegger): um dizer, um ter a dizer, um dizer aquilo que resta, dizer o nosso horror porque toda obra de arte é feita de horror. Como prefere Joaquim Cardozo, agora numa perspectiva ambivalente, ou seja, bipolar: dizer é compor um volume vazio, tocar o ponto furo da imagem em seu volume no vazio intangível, ou seja, dizer é não abrir mão da responsabilidade ética de dizer, como uma resistência.

\footnotetext{
${ }^{6}$ CARDOZO. Poesia completa.

${ }^{7}$ DIDI-HUBERMAN. Memórias de cego - o auto-retrato e outras ruínas, p. 36.

${ }^{8}$ Esse poema de Horácio Dídimo faz parte do seu livro intitulado O passarinho carrancudo [Fortaleza, Edição do Autor, 1983, p. 12]: "é você o contador de histórias / que ganha o mundo / dizendo cousas do arco da velha?// pois eu vim tomar uma satisfação".
}

${ }^{9}$ DEGUY. Reabertura após obras, p. 71. 
Dessa forma-formante, o pacto do cupim com os objetos e o mundo, ponto furo na imagem, é possível pensar que todo princípio de transgressão é originalmente desordem, como sugeriu Raúl Antelo (numa insistência pertinente de que ler é ver) ao comentar a poesia de Murilo Mendes seguindo Bataille:

A transgressão como princípio de uma desordem organizada, na medida em que introduz, no mundo organizado, algo que o ultrapassa, o caráter organizado a que tiveram acesso aqueles que a praticam; mas é bom notar que essa organização, fundada no trabalho, descansa, por sua vez, na descontinuidade. ${ }^{10}$

Para ele, tanto uma reação que procura reencontrar a continuidade perdida quanto uma que busque atribuir imortalidade às coisas descontínuas harmonizam-se no Cristianismo, ou seja, que toda impureza é rejeitada. A questão é, ou passa a ser, como tocar de muito perto a impureza. Assim, me parece, é possível agora e ainda ficar diante do poema.

\title{
DIGRESSÃO
}

O escritor português Gonçalo M. Tavares, num de seus projetos esféricos, entre o reino e a glória, intitulado O bairro (nem poema, nem prosa, logo, poema e prosa, tanto faz, porque não mais o verso, mas agora a linha, o traço, o vestígio, a queda da prosa ou a preocupação com "o caráter corporal da vida", como Alonso Quijada, o Quixote, preocupado com seus dentes muito mais valiosos que diamantes: os dentes que doem, os dentes que faltam, lembra-nos Milan Kundera ${ }^{11}$ ). Para $O$ bairro, Gonçalo justapõe uma série de senhores retirados de um cânone pessoal de leitura e os torna vizinhos entre aproximação e distância, para

\begin{abstract}
reatar pela heterologia aqueles que pareciam tão estranhos um ao outro a ponto de não pertencer ao mesmo mundo. Distanciar é escavar o abismo sob a familiaridade, desemparelhar para intensificar a vizinhança, (...), afrouxar os intervalos, refazer a espacidade, dar novo interesse ao disparatado. ${ }^{12}$
\end{abstract}

No livro intitulado O senhor Calvino, por exemplo, a procura é a de recuperar o risco imaginativo de Italo Calvino, que é quase o de Cyrano, por uma "razão poética" (roubar a lua, por exemplo, e dar de presente a quem se ama), e num pequeno texto chamado $\mathrm{O}$ animal de Calvino, o que em português é quase ambíguo, ele diz:

\footnotetext{
${ }^{10}$ ANTELO. Ausências, p. 81.

${ }^{11}$ KUNDERA. A cortina, p. 16.

${ }^{12}$ DEGUY. Reabertura após obras, p. 91.
} 


\section{"O animal de Calvino"}

DE MANHÃ, CALVINO dirigia-se à cozinha para dar de comer ao Poema. O bicho devorava tudo: nenhum alimento era desagradável ou esquisito e tudo para ele parecia ser alimento.

Ao fim do dia, depois de terminadas as tarefas urgentes, o senhor Calvino acariciava-lhe o pêlo com a delicadeza e a hábil distração aparente dos tocadores de harpa. Naqueles instantes, o universo abrandava as rotações ganhando a lentidão inteligente dos pequenos felinos.

Dar banho ao Poema não era fácil; ele como que resistia à limpeza, exigindo de modo saltitante uma liberdade impudica que só a sujidade permite. Mas bem pior ainda era dar ao bicho uma injeção. Era a única altura em que as garras eram dirigidas a Calvino. Aquele animal preferia adoecer, a ser medicado.

Um dia o animal caiu da janela do $2 \mathrm{o}$ andar, e morreu.

Calvino, no dia seguinte, adotou outro.

E deu-lhe o mesmo nome. ${ }^{13}$

A preferência pela resistência à limpeza, por uma liberdade impudica que só a sujidade permite, pelo adoecimento e não pela saúde e a opção pelo acidente que acarreta a morte, é que metamorfoseia o animal ao seu nome e o nome ao animal; é a imagem do poema que está em jogo, sem pé e sem cabeça, o poema como aquilo que se repete como diferença depois de sua própria morte. $O$ pensamento animal, diz Derrida, cabe à poesia. Didi-Huberman, por sua vez, diz sobre os enganos do pensamento, que constituem, de certa forma, a ambivalência da imagem no seu texto sobre a imagem mariposa. Afirma que é um erro acreditar que a coisa está quando ela aparece, e que ela permanece, resiste, persiste tal qual no tempo como em nosso espírito, que a descreve e conhece. Como se dizer de uma imagem e, ainda assim, mantê-la viva, fosse levar em conta o ponto de vista temporal de sua fragilidade. E completa: o que já não está permanece, resiste, persiste tanto no tempo como em nossa imaginação, que rememora. Ou seja, a imago, para Didi-Huberman, é aparição visual e, ao mesmo tempo, experiência corporal. ${ }^{14}$ Assim, a imago - como o poema - traz o paradoxo da forma e do informe contido na metamorfose, esta ambivalência - este processo através do qual um ser imundo, um verme (como um rato ou um cupim), é capaz de refazer-se num "renascimento" com algum esplendor.

É, por fim, no poema de Max Martins, intitulado "O animal sorri", de seu livro H'era, de 1971 (coetâneo ao poema de Joaquim Cardozo), livro que demarca um projeto poético em torno dos usos da linguagem como um corpo animalizado, como uma rasura, quando ele toma o poema como um "semidestroçado frêmito de um destino cego de antemão", como aquilo que "não mais aceita o rito do ofício: O ofício", como uma rasura do corpo esquecido - o esquecimento - a partir do "desabitado segredo das palavras", que podemos suspeitar que o poema, se um ser, assim como o animal, vê,

${ }^{13}$ TAVARES. O senhor Calvino, p. 25.

${ }^{14}$ DIDI-HUBERMAN. La imagem mariposa, p. 65. 
mesmo que vesgo ou zarolho; e por isso, ironicamente, sorri, numa espécie de aparição exemplar como um negativo da verdade, um "não importa que". Diz o poema:

$$
\text { "O animal sorri" }
$$

O animal sorri. Seus dentes

são rochas

e ruínas

por onde a noite

sem memória desce

sua demência.

Teu corpo (ainda leve)

- indelével sombra

\section{sobra}

duma remota juventude

está de volta.

Ninguém te segue, e cega

a ave fere a tarde

te anuncia

às febres desde dia.

Rios se desesperam

pedras agonizam

se torturam

se procuram.

(Virás à jaula

deste animal remanescente

do fogo e do Dilúvio?

Atraiçoado

oco

ex-

posto em praça pública

para os olhos

das crianças, dos fotógrafos?

EU-COBERTO-DE-PELOS: virás me ver

atrás das grades?) ${ }^{15}$

O poema é um convite a ver a imagem de um glifo do homem e do animal [um traço feito com cinzel, gravado em relevo, entalhado], um eu-coberto-de-pelos, expressão que está grafada no poema com letras altas, porque há uma exposição do riso do animal

${ }^{15}$ MARTINS. Não para consolar, p. 262. 
em praça pública para os olhos das crianças - estes "Pequenos animais agarrados ao vício de existir pode que se transformem no acabado projeto de um ser humano" com a sua previsível catástrofe ${ }^{16}$ - e para o olhar dos fotógrafos - com uma outra visão para o mundo e para o observador, um punctum ${ }^{17}$ em busca do olhar perdido daquilo que a fotografia diz -, com uma interrogação propositiva e desafiadora, própria do poema, um ethos, um DIZER: virás me ver atrás das grades? A linguagem fala-se, ela nos fala sempre da cegueira (cecité) que a constitui, aponta Derrida. Pensar o poema como um animal que ri é armar uma proposição que ao mesmo tempo que desfaz o caráter humano termina também por refazê-lo e reconduzi-lo a uma vertente deliberada de instinto e desejo, mais ou menos quando o desejo de saber ver (uma indicidibilidade: vontade de saber savoir / vontade de ver - voir) fica mais perto uma natureza da vontade, de um estado natural, como sugeriu Montaigne. ${ }^{18}$ E assim, se visitados por um vampiro, por exemplo, podemos convidá-lo pra um café e, juntos, ir ao cinema do bairro, como fez Drummond, em uma de suas Canções de alinhavo. Ou seja, parar a reiteração automática da natureza.

\section{A}

\section{A B STRACT}

This paper starts from Gonçalo M. Tavares's short narrative titled "O animal de Calvino" and Max Martin's poem , "O animal sorri", to establish a line of thought that tries to describe the place of the poet in a post-human perspective, between the creation of an ethos and the mobile and political center of time nowadays.

\section{KEYWORDS}

Poem, politics, animality

\section{REFERÊNCIAS}

ANDRADE, Carlos Drummond de. Corpo. Rio de Janeiro: Record, 2002.

ANTElO, Raúl. Transgressão e modernidade. Ponta Grossa: UEPG, 2001.

ANTELO, Raúl. Ausências. Florianópolis: Editora da Casa, 2009.

BUENO, Wilson. Manual de zoofilia. Ponta Grossa, PR: UEPG, 1997.

BRASIL, Assis. Os que bebem como os cães. Rio de Janeiro: Nórdica, 1975.

CARDOZO, Joaquim. Poesia completa. Rio de Janeiro, Civilização Brasileira, 1979.

CARVAlHO, Flavio. A origem animal de Deus. São Paulo: Difusão Europeia, 1973.

DEGUY, Michel. Reabertura após obras. Trad. Marcos Siscar e Paula Glenadel. Campinas: EdUnicamp, 2011.

\footnotetext{
${ }^{16}$ BUENO. Manual de zoofilia, p. 41.

${ }^{17}$ Para Roland Barthes o punctum é o campo cego da fotografia.

${ }^{18}$ MONTAIGNE. Ensaios, p. 481.
} 
DERRIDA, Jacques. Memórias de cego - o auto-retrato e outras ruínas. Trad. Fernanda Bernardo. Lisboa: Fundação Calouste Gulbenkian, 2010.

DIDI-HUBERMAN, Georges. La imagem mariposa. Trad. Juan Jose Lahuerta. Barcelona: Mudita \& Co., 2007.

KUNDERA, Milan. A cortina. Trad. Teresa Bulhões. São Paulo: Cia das Letras, 2005.

MACEDO, Joaquim Manuel de. A luneta mágica. Fortaleza: Fundação Demócrito Rocha, 2001.

MARTINS, Max. Não para consolar. Belém: CEJUP, 1992.

MONTAIGNE. Ensaios. In: . Os pensadores. Trad. Sérgio Milliet. São Paulo: Abril Cultural, 1972.

TAVARES, Gonçalo M. O senhor Calvino. Rio de Janeiro: Casa da Palavra, 2007. 